\title{
Longitudinal annoyance responses to a road traffic noise management strategy that reduced heavy vehicles at night
}

\author{
A. L. Brown ${ }^{\text {a) }}$ \\ Urban Research Program, Griffith School of Environment, Griffith University, Nathan 4111, \\ Brisbane, Australia
}

(Received 15 October 2013; revised 23 May 2014; accepted 12 November 2014)

\begin{abstract}
A traffic management strategy was designed to reduce trucks using an urban corridor. The intervention had potential to affect night-time truck flows, but did not target truck traffic in the day, or vehicles other than trucks at any hour. A two-year long panel study measured the community's response to this intervention, using five repeated measurements of response. There were significant reductions in the panel's response to noise, both for night-time annoyance and for interference with activities. This was remarkable given that noise monitoring showed that the intervention produced no change in conventional traffic noise indicators. However, there were measureable changes in the number of articulated truck movements at night, and the benefit can be attributed to reduction in the number of noise events from heavy vehicles. The parallel tracking of changes in reported noise effects and the numbers of heavy vehicles in the night hours in this longitudinal study provides strong support to the notion that noise effects at night depend on the number of noise events experienced, not only on the overall level of traffic noise. The latter appear to be unresponsive indicators by which to assess the noise-effect benefit of heavy vehicle reduction strategies.
\end{abstract}

(C) 2015 Acoustical Society of America. [http://dx.doi.org/10.1121/1.4904517]

[LMW]

Pages: $165-176$

\section{INTRODUCTION}

\section{A. Reduction in night-time truck flow}

An $11 \mathrm{~km}$ roadway through an urban corridor in Brisbane, Australia, links several motorways and industrial areas. The roadway carries four or six lanes of traffic in different sections, with posted speed limits of 60 to $80 \mathrm{~km} / \mathrm{h}$. It is an important regional freight route characterized by relatively high proportions of commercial vehicles, particularly articulated heavy vehicles, at night. This roadway also has fronting residential properties (Fig. 1).

In response to community demands to provide relief from the effects of road traffic noise at night for those living adjacent to this roadway, authorities instigated measures to reduce the number of heavy vehicles using the corridor; noise barriers could not be used as most properties required direct access from the study roadway. Truck restriction strategies can be implemented for a range of operational, safety, or environmental reasons (Transportation Research Board, 2003), and the trial measure implemented in this study was the removal of a toll for heavy vehicles on a route parallel to the study corridor to entice some heavy vehicles to reroute voluntarily to the toll roadway (referred to here as the truck diversion strategy). With the intent to reduce noise from heavy vehicles during the hours when most residents along the corridor were sleeping, the toll removal operated only during the night hours (22:00 $\mathrm{h}$ to $05: 00 \mathrm{~h}$ ). There is some indication that the shoulder hours of the night sleep period could be particularly important with regards to reducing

\footnotetext{
a) Author to whom correspondence should be addressed. Electronic mail: Lex.Brown@griffith.edu.au
}

sleep disturbance (Griefahn and Spreng, 2004), but the hours of operation of the toll removal had previously been set by the authorities, presumably based on operational traffic flow considerations. The trial would have no direct effect on heavy vehicle flows on the corridor during the day-time hours, or on traffic other than trucks at any time. ${ }^{1}$

To ascertain the efficacy of these measures, the responsible authority funded three monitoring activities: traffic flows on the study corridor, road traffic noise levels adjacent to the study roadway, and responses of residents living along the corridor to road traffic noise. The community survey consisted of a longitudinal panel study over nearly two years

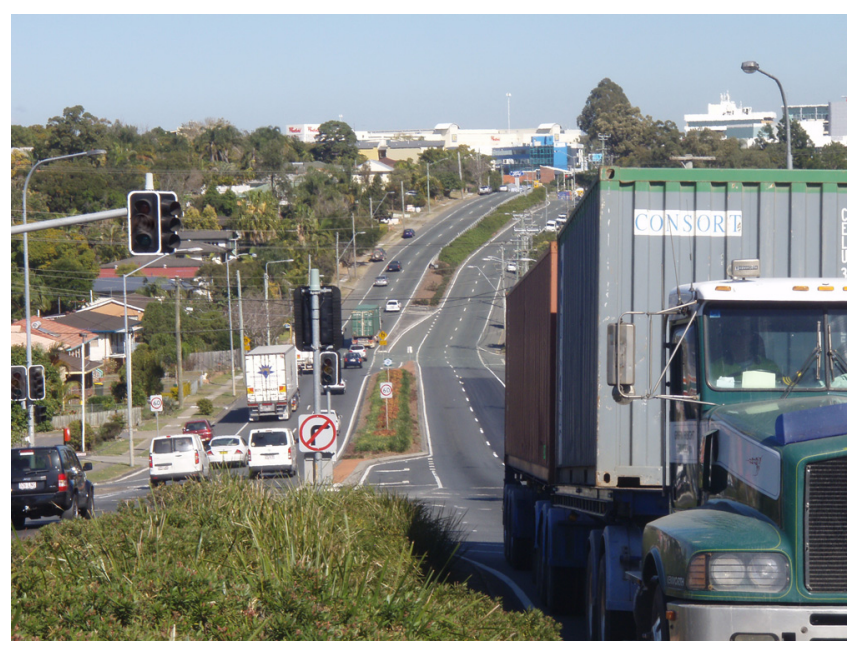

FIG. 1. (Color online) A short section of the $11 \mathrm{~km}$ urban corridor where the roadway is a two-way four-lane roadway with a median strip. The corridor carries some 40000 to 50000 vehicles per day, with up to $15 \%$ heavy vehicles. Note the residential dwellings in proximity to the roadway on the left of the photograph - typical of much of the corridor. 
with one before, and four after, repeated measurements of noise effects on each respondent in the panel. Designs such as this, that measure community response to road traffic noise longitudinally, are not common.

The expectation of the truck diversion strategy was that it would result in some change in residents' road traffic noise exposures through reduction in the number of high noise level trucks passages at night, though there was no expectation that the interventions would change levels of day-time traffic noise exposures. The community study was designed specifically to ascertain if the night-time truck diversion resulted in change in noise effects for those living in the corridor.

This paper examines and reports the following.

(1) Practical application of a design protocol for a longitudinal study of community response to change in noise exposure.

(2) Repeated noise annoyance and activity interference measurements on a panel over nearly two years, together with measurement of factors known to moderate annoyance.

(3) The longitudinal relationship of changes in night-time noise effects in the panel with change in traffic flow and noise indicators resulting from the diversion strategy.

\section{B. Heavy vehicles and road traffic noise}

Heavy vehicles have noise level emissions higher than cars (IMAGINE, 2007) with mean measured $A$-weighted pass-by levels of articulated vehicles some 6 to $8 \mathrm{~dB}$ higher, on roadways with traffic speeds of $60-100 \mathrm{~km} / \mathrm{h}$ (Brown and Tomerini, 2011). An increase of heavy vehicles in the traffic mix can elevate the noise level indicator $L_{\mathrm{eq}}$ (or $L_{10}$, or $L_{\mathrm{eq}}$ derivatives such as $L_{\text {den }}$ or $L_{\text {night }}$ ) and traffic mix is an input parameter in road traffic noise level prediction models (for example, FHWA, 2008).

\section{STUDY DESIGN}

\section{A. Assessing response to change in exposure}

To investigate if the truck diversion resulted in changes of noise effects on the community, the study design was based on the model for assessment of community response to a change in noise exposure proposed by Brown and van Kamp (2005)_as in Table I. A longitudinal design is required because reviews of intervention studies (Brown and van Kamp, 2009a; van Kamp and Brown, 2013) found, for changes in road traffic noise exposure where the source of noise changes (type 1 changes), large and persistent changeeffects in annoyance beyond those expected from the change in noise levels alone.

Annoyance responses are related to respondents' personal and situational variables, not only to level of noise exposure (Fields, 1993; Job, 1999; Miedema and Vos, 1999, 2003). Most demographic factors have little effect on annoyance, but some personal and attitudinal factors do, such as overall opinion of the neighborhood, noise sensitivity, fear regarding danger from the source, and aspects such as
TABLE I. The longitudinal design model for studying change (adapted from Brown and van Kamp, 2005). With a change in noise exposure between $t_{0}$ and $t_{1}$, sequential measurements of effect are undertaken before and after the change, preferably with multiple after measurements $\left(A_{-1}, A_{0}\right.$, $\left.A_{1}, A_{2}, \ldots, A_{x}\right)$. Repeated measurements are also made of activity interference $\left(\mathrm{Act}_{x}\right)$, noise sensitivity $\left(\mathrm{Sens}_{x}\right)$, coping strategies $\left(\mathrm{Cop}_{x}\right)$, and a range of attitudinal, retrospective, and prospective assessments.

\begin{tabular}{|c|c|c|c|c|}
\hline Sequential measurements & before $_{-1}$ & before $_{0}$ & after $_{1}$ & $\operatorname{after}_{2}, \ldots$ \\
\hline Time & $t_{-1}$ & $t_{0}$ & $t_{1}$ & $t_{2}, \ldots$ \\
\hline Noise exposure & $L_{-1}$ & $L_{0}$ & $L_{1}$ & $L_{2}, \ldots$ \\
\hline \multicolumn{5}{|c|}{ Effect measures (or respondent attribute measures) } \\
\hline Annoyance & $A_{-1}$ & $A_{0}$ & $A_{1}$ & $A_{2}$ \\
\hline Activity interference & Act $_{-1}$ & Act $_{0}$ & Act $_{1}$ & $\mathrm{Act}_{2}$ \\
\hline Retrospective annoyance & & & $\mathrm{RA}_{01}{ }^{\mathrm{a}}$ & $\mathrm{RA}_{02}$ \\
\hline Noise sensitivity & Sens $_{-1}$ & Sens $_{0}$ & Sens $_{1}$ & $\mathrm{Sens}_{2}$ \\
\hline Attitudes to authorities, etc. & Ats $_{-1}$ & $\operatorname{Ats}_{0}$ & Ats $_{1}$ & Ats $_{2}$ \\
\hline Opinion of neighborhood & Neigh $_{-1}$ & $\mathrm{Neigh}_{0}$ & $\mathrm{Neigh}_{1}$ & $\mathrm{Neigh}_{2}$ \\
\hline Coping strategies & Cop $_{-1}$ & Cop $_{0}$ & $\operatorname{Cop}_{1}$ & $\mathrm{Cop}_{2}$ \\
\hline Prior knowledge & - & $X_{10}^{\mathrm{b}}$ & - & - \\
\hline Expectations & - & $Y_{10}{ }^{\mathrm{b}}$ & - & - \\
\hline Steady-state controls & \multicolumn{2}{|c|}{ Before control } & \multicolumn{2}{|c|}{ After control } \\
\hline
\end{tabular}

${ }^{\mathrm{a}} \mathrm{RA}_{01}$ is a respondent's retrospective assessment of annoyance at $t_{1}$ of conditions that existed at $t_{0}$.

${ }^{\mathrm{b}} X_{10}$ and $Y_{10}$ are respondent's prior knowledge, and expectations, at $t_{0}$, of conditions that will exist at $t_{1}$.

preventability of the noise and attitudes towards the noise source. In change situations, a respondent's reaction to the change may also be influenced both by perceptions of the responsible authority's concern for the affected community and by expectations of the proposed change (Brown and van Kamp, 2009b).

The design adopted was a longitudinal panel study consisting of five rounds of face-to-face interviews with repeated measures of all relevant outcomes and factors. Small deviations from the generic design of Table I included only one survey before the truck strategy was implemented, and no control sites matching the before and after conditions, neither being feasible in the current study.

\section{B. The sequence of monitoring activities}

The timing of the five repeated measures of community response (CR1-5) is shown in Table II. The table also shows the repeated measures of traffic counts on the corridor (TF16) and of noise level measurements (NL1-6). Because of jurisdictional and funding issues, each of the three monitoring activities was carried out by different organizations. Some changes in the program occurred administratively during implementation. For example, community response measurements were initially designed to test the effectiveness of the toll-free trial only for one year after it began, ending with $\mathrm{CR} 4$, but authorities requested then that a further round of measurements be conducted in year 2 (CR5). As will be seen below, this had some consequences for retained sample size and some aspects of the survey. Noise level monitoring continued for nine months after the toll-free trial ended (not shown in Table II). 
TABLE II. Monitoring activities over the near two years of the truck diversion strategy including six repeated measures of traffic flow, six of noise levels, and five of community responses to noise.

\begin{tabular}{|c|c|c|c|c|c|c|}
\hline \multirow{3}{*}{$\frac{\text { Measurements }}{\text { Traffic flow TF1-6 }}$} & \multirow{3}{*}{$\begin{array}{c}\text { Before } \\
\text { TF1 Feb }\end{array}$} & \multicolumn{5}{|c|}{ Toll-free trial (truck diversion strategy) } \\
\hline & & \multicolumn{2}{|c|}{ Year 1} & & \multicolumn{2}{|c|}{ Year 2} \\
\hline & & TF2 Apr & TF3 Jun & TF4 Oct & TF5 Feb & TF6 Nov \\
\hline Noise level NL1-6 & NL1 Feb & NL2 Apr & NL3 Jun & NL4 Oct & NL5 Feb & NL6 Nov \\
\hline Community response CR1-5 & CR1 Feb & \multicolumn{2}{|c|}{ CR2 May } & CR3 Oct & CR4 Mar & CR5 Nov \\
\hline
\end{tabular}

\section{Panel selection for the community response study}

There were 370 dwelling units along the corridor that were a single-lot residence with a shared property boundary with the road corridor, or a unit in a multiple-dwelling building that had no other buildings between it and the road corridor, and at least one of its windows facing the road corridor. The responsible road authority wrote to this study population advising them of the on-going program to improve traffic conditions and residential amenity in the study corridor, and that a survey of residents was underway and that it included their views on road traffic noise. A newsletter announcing details of the toll-removal trial, together with other planning and traffic works along the corridor, had been delivered previously to all residences.

The panel sample of adults who had lived at that address for at least six months was drawn randomly from this population of 370, with one per dwelling unit, and with equal numbers of males and females. The target was a panel size of 100. Sampling was with replacement when the selected dwelling was not occupied or there was no answer after four calls back (10\% of dwellings approached), where interviews were refused $(3 \%)$, where the interview could not be conducted in English (3\%), or where there were dogs or other perceived hazards to interviewers $(6 \%)$. The resultant panel size for the before-study was 99 respondents. Some $70 \%$ of the panel lived in owner-occupied dwellings, and the age distributions of respondents, and their length of residency in the current dwelling, are shown in Table III. The median setback of the facade of the dwellings of panel members from the centerline of the nearside roadway was $18 \mathrm{~m}$, with $80 \%$ of the dwellings located between 14 and $32 \mathrm{~m}$ from the roadway.

The first after-survey was conducted three months after the truck diversion trial began, with three more after-surveys over the next 18 months. The panel technique required reinterviewing the same individuals at each round of the survey. At CR1, all respondents had agreed to continue in the panel. Over time, the panel size reduced as people interviewed in

TABLE III. Distribution of age of the panel and the length of their residency in the current dwelling $(n=99)$.

\begin{tabular}{lcccccc}
\hline \hline & $16-24 \mathrm{yr}$ & $25-34 \mathrm{yr}$ & $35-44 \mathrm{yr}$ & $45-54 \mathrm{yr}$ & $55-64 \mathrm{yr}$ & $65+\mathrm{yr}$ \\
\hline $\begin{array}{l}\text { \% within } \\
\text { category }\end{array}$ & $14 \%$ & $17 \%$ & $20 \%$ & $20 \%$ & $9 \%$ & $19 \%$ \\
& $6-12$ months & $1-2 \mathrm{yr}$ & $2-5 \mathrm{yr}$ & $6+\mathrm{yr}$ & & \\
$\begin{array}{l}\% \text { within } \\
\text { category }\end{array}$ & $16 \%$ & $12 \%$ & $28 \%$ & $44 \%$ & \\
\hline \hline
\end{tabular}

the first round moved away, declined to remain in the panel, or were otherwise unavailable for subsequent interview. Table IV shows the panel size at each of the after-surveys CR2 through CR5. Note that the community survey was originally designed to terminate after CR4 but authorities requested, after CR4 was completed, that it be extended to CR5. For the reinterviews, six calls-back were required before a respondent was recorded as unavailable. The overall drop-out rate shown in the table includes all causes of noninterview. For example, of the $23 \%$ drop-out at CR2, $11 \%$ was due to the respondent no longer living at that address, $7 \%$ to non-availability after six calls back, $1 \%$ were temporarily living elsewhere, $1 \%$ were ill, and only $3 \%$ refused to be re-interviewed. Several of the latter indicated their refusal was based on perceived frustration with the toll removal trial not improving their environmental situation, so why continue to participate? Clearly this is not a random drop-out from the panel but it was a very small percentage of panel size and the effects of this on the overall results of the study likely to be small. The reduction in panel size changed its demographic composition towards overrepresentation of older, female owner occupiers, as a high proportion of the dropout was of younger males who lived in rented accommodation. Effects of drop out on annoyance scores is examined further in Sec. V C.

\section{The questionnaire}

The survey used trained interviewers and a structured questionnaire that included the noise effects and personal attributes listed in Table I.

(1) Annoyance with road traffic noise was measured according to the ISO (2003) procedure, but using a scale of 0 to 9. Scale end points were labeled not at all and extremely. Annoyance was measured twice within each interview, the first time without specifying any particular part of the day, the second asking specifically about the late night and very early morning. Highly annoyed has been scored as any of 7, 8, or 9 on the annoyance scale,

TABLE IV. Number of respondents interviewed, and drop-out rate, at the before (CR1) and the four after interviews (CR2-5).

\begin{tabular}{lccccc}
\hline \hline & & \multicolumn{4}{l}{ Four after-surveys (over 20 months) } \\
\cline { 3 - 6 } & Before-survey & May & Oct & Mar & Nov \\
\hline \multirow{3}{*}{ Number of respondents } & CR1 & CR2 & CR3 & CR4 & CR5 \\
Drop-out rate & 99 & 76 & 61 & 45 & 33 \\
\hline \hline
\end{tabular}


annoyed as 5 or 6 , and a little annoyed as 3 or 4 . Both annoyance and activity interference questions were preceded by thinking about the last two months.

(2) Activity interference was measured by self reports of the frequency with which traffic noise disturbed sleep, interfered with communication, or startled the respondent, each on the same four-point scale: never, sometimes, a lot, nearly all the time.

(3) One coping strategy was measured: the frequency of having to shut the windows because of traffic noise. Again this was measured twice: first without specifying $a$ period, then again for the late night and very early morning.

(4) Opinion of the neighborhood was rated on a four point scale: excellent, good, poor and very poor.

(5) Noise sensitivity was measured by a precursor of the Weinstein noise sensitivity scale: the General Noise Annoyance questionnaire (see Hill, 2012; Belojević et al., 1997). Respondents were categorized as being of low, medium, and high sensitivity using tertile cut-offs.

(6) For prior knowledge and expectations, respondents were asked (a) if they were aware that their household had been involved in consultations with government about the urban corridor (b) if they were aware that a truck management strategy was planned for the corridor, and (c) about their current expectations as to whether these strategies would lead to an improvement in terms of noise at their dwelling. They were also asked (d) if anyone in their household was employed in the truck transport industry.

The pre- and post-treatment questionnaires contents were largely identical, though questions on consultations, prior knowledge, expectations and truck industry employment were asked only in the pre-treatment survey. The posttreatment questionnaires additionally asked if respondents had noticed changes in road traffic noise and its effects since before the truck management strategy began. This was asked at the end of the questionnaire so as not to bias previous responses on noise effects.

\section{ANALYSIS}

The outcomes of interest are the annoyance scores of respondents and the frequency of activity interference caused by road traffic noise. Across survey rounds CR1-CR5, there were 314 separate measurements of each of the annoyance and activity interference responses (99 in the before survey CR1; 76 in CR2; 61 in CR3, 45 in CR4, and 33 in CR5). This full data set is used below to examine interrelationships (cross-tabulations and Spearman rank order correlations) between annoyance scores and activity interference outcomes.

However, to achieve the primary aim of testing for change in noise outcomes as a result of the truck diversion trial, it is necessary to take into account that repeated scores of any one individual are not independent across successive surveys, and also that the panel size decreased across CR1-CR5. The MIXED procedure in sPSS (linear mixedeffects modeling: IBM sPSS STATISTICS, Version 21) was utilized as its assumptions allow both correlation between repeated measures on the same individual and an unbalanced design resulting from the reducing panel size. The MIXED procedure provides tests, over the duration of the truck diversion trial, for changes in the mean value of noise response variables predicted in the fitted models.

\section{RESULTS}

\section{A. Annoyance and activity interference outcomes}

The interrelationships between the two available annoyance scores (annoyance when no specific period of the day had been specified, and annoyance during the late night and very early morning) and the frequency of the reports of traffic noise interference with activities are reported below based on all 314 of the outcome measurements available. It can be noted though, that analyses using only the 99 outcomes of the panel at the before-survey round, CR1, produced almost identical results.

The two different annoyance scores should not be interpreted as "annoyance in the daytime" and "annoyance in the night-time" [see Hoeger et al. (2002) who reported that, for road traffic noise, global annoyance judgments do not differ substantially for day and night-time]. Of the two scores, the first is the measure of annoyance according to ISO (2003) which seeks a general reaction to the noise source in the respondent's home. That reaction is presumed to be globalintegrated over a considerable, but non-specified, period, but generally assumed to be annoyance over a "whole day." The second is annoyance specific to the late night and very early morning hours alone-it being appropriate to have respondents additionally focus on these night hours in this study because the truck diversion could affect noise only at night.

The correlation between the two annoyance scores is 0.64 (see Table V). Figure 2(a) shows details of the joint reporting of these two scores, and that many in the panel reported night-time annoyance scores that mirrored, but were just marginally lower, than scores reported according to the ISO question. Given the reasonable correlation between them, either score could be used, but given the traffic management intervention applied for 22:00 h to 05:00 h only, further examination below of the change in annoyance over the duration of the truck diversion strategy will be based on the annoyance scores for the late night and very early morning.

Table $\mathrm{V}$ shows that there is reasonable consistency between each of the annoyance scores and the range of activity interferences, with correlation coefficients ranging from 0.32 to 0.64 . Higher annoyance scores are associated with a greater incidence of interference with activities. Annoyance at night has its highest correlation (0.64) with sleep interference, and is also highly related to being startled at night (0.61). Both sleep disturbance and startle are effects of noise likely to be triggered by noise events in the road traffic stream.

Figure 2(b) shows that a high proportion of respondents report they shut their windows all the time over both of the periods. Over three quarters of all respondents in a subtropical city shutting windows all the time because of road traffic 
TABLE V. Spearman rank order correlations between annoyance scores and activity interferences caused by noise (shutting windows; trouble hearing radio/ television or talking on telephone; disturbance to sleep or startled) when no part of the day was specified in the question, and for the "late night and very early morning hours" period. All correlations are significant at 0.01 level $(n=314)$.

\begin{tabular}{|c|c|c|c|c|c|c|c|c|}
\hline & & \multicolumn{3}{|c|}{ No period specified } & \multicolumn{4}{|c|}{ Late night \& early morning } \\
\hline & & Annoyance & Shut windows & Hearing & Annoyance & Shut windows & Sleep & Startled \\
\hline \multirow[t]{3}{*}{ No period specified } & Annoyance & 1.0 & 0.36 & 0.53 & 0.64 & 0.39 & 0.47 & 0.51 \\
\hline & Shut windows & & 1.0 & 0.38 & 0.32 & 0.74 & 0.33 & 0.35 \\
\hline & Hearing & & & 1.0 & 0.42 & 0.33 & 0.39 & 0.40 \\
\hline \multirow[t]{4}{*}{ Late night \& early morning } & Annoyance & & & & 1.0 & 0.41 & 0.64 & 0.56 \\
\hline & Shut windows & & & & & 1.0 & 0.42 & 0.38 \\
\hline & Sleep & & & & & & 1.0 & 0.61 \\
\hline & Startled & & & & & & & 1.0 \\
\hline
\end{tabular}

noise, is a fair indicator of the severity of the traffic noise problem for the community living along this corridor. The correlation between shutting windows (no part of the day specified) and shutting windows (late night and very early morning) is high, at 0.74 . However, differences in window shutting behavior emerge between these two periods, with $13 \%$ of those who reported they shut their windows a lot or nearly all the time when no period was specified, also reported that they never, or only sometimes, shut their windows at night. This fits with previous reports (WHO, 2009) of a preference for some residents to sleep with windows open even where traffic noise exposures are high.

\section{B. Noise exposures and levels of annoyance}

Road traffic noise exposures of the dwellings of the panel were high. The mean $A$-weighted road traffic noise level, $L_{\mathrm{den}}$, at the facade of the 99 dwellings was $70 \mathrm{~dB}$.

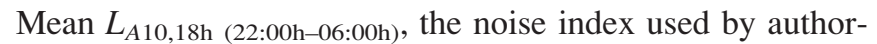
ities in the study area, was $72 \mathrm{~dB}$. Facade reflection was not included. Variation in the setbacks of dwelling in the panel from the roadway resulted in some variation of facade exposures, but $90 \%$ of all dwellings in the panel were exposed to levels within -5 to $+2.5 \mathrm{~dB}$ of this mean.

Given such high levels of exposure, the annoyance scores reported by the panel were also high. For example, at $\mathrm{CR} 1$, prior to the commencement of the truck diversion, the percentage of the panel who reported they were highly annoyed was 70\% (the percentage of the panel who reported they were highly annoyed during the late night and very early morning was 58\%). This is a much greater proportion than would be predicted from the synthesis of road traffic noise exposure-response relationships by Miedema and Oudshoorn (2001). At equivalent exposures to those in the present study (for example, at $L_{\mathrm{den}}$ levels of 65, 67.5, 70, and $72.5 \mathrm{~dB}$ ), Miedema and Oudshoorn (2001) estimated that the

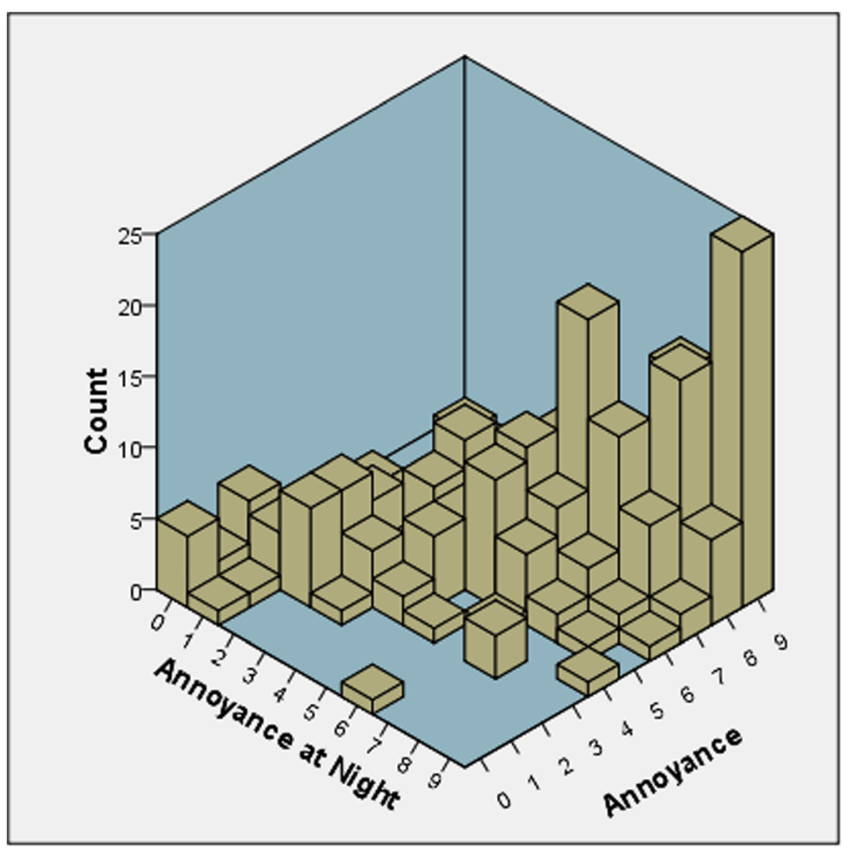

(a)

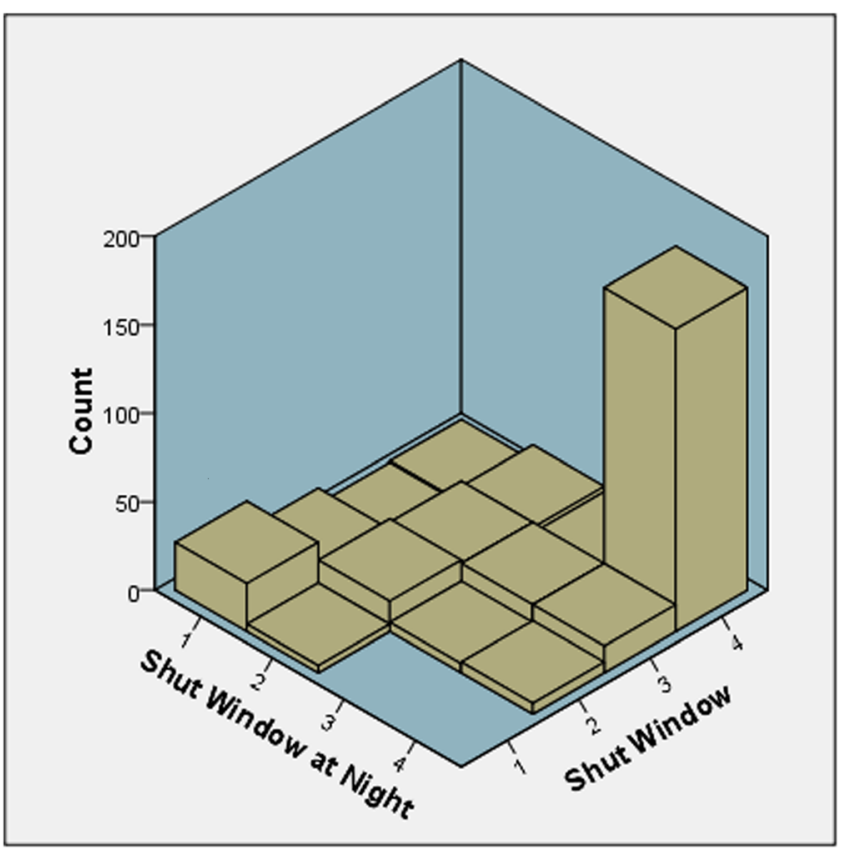

(b)

FIG. 2. (Color online) Relationships for (a) annoyance ( $0=$ not at all, $9=$ extremely) and (b) shutting windows $(1=$ never, $2=$ sometimes, $3=$ a lot, $4=$ nearly all the time) between responses when no part of the day was specified in the question and when responses were sought specifically for the late night and very early morning period. $n=314$. 
proportion of any exposed population highly annoyed would be $16 \%, 20 \%, 25 \%$, and $30 \%$, respectively.

There is no direct evidence in the present study to explain why the panel reported such high levels of annoyance with before conditions, but feasible explanations (though see Sec. V D below) may include the attitudinal factors that are known to affect annoyance scores. For example, the panel had a high degree of awareness that: the truck diversion trial was planned and about to be implemented; there were ongoing community consultations between the responsible road authority and the community regarding issues concerning the study roadway; and respondents had been informed by the original letter to the community that the present survey, while conducted by a university research team, was funded by the road authority. Furthermore, the Miedema and Oudshoorn (2001) curves are a synthesis of a large number of study results, and the exposure-response curves from individual studies that were used in this synthesis themselves varied widely.

In any case, the important question in this study is not the absolute level of annoyance in the community, but whether this level changed over the duration of the study in response to the truck diversion strategy.

\section{Change in community response during the truck diversion strategy}

\section{Change in mean annoyance scores of the panel}

Over the 22 months of the truck diversion trial, the community surveys provided five repeated measures of annoyance with late night and very early morning traffic noise. Individual night-time annoyance scores were modeled, across the survey rounds, as the dependent variable using the SPSS MIXED procedure, with noise sensitivity, opinion of the neighborhood, and other respondent attributes, all entered in the model. These factors, all known to be related to annoyance (e.g., Guski, 1999; Fields, 1993) are listed below, and the values entered in the initial model were those as measured in the before study CR1.

(1) Respondent's noise sensitivity.

(2) Respondent's overall opinion of the neighborhood.

(3) Awareness they or a family member had consultations with the road authority (26\% of the panel were aware there had been consultations).

(4) Awareness of the truck management strategy (58\% of the panel reported they were aware of the trial).

(5) Expectations as to whether this would result in an improvement $(66 \%$ of the panel thought that the truck management strategy could lead to an improvement).

(6) A household member was involved in the truck transport industry (6\% of the panel had reported a household association with the trucking industry).

(7) Interaction effects between survey round and each of noise sensitivity and neighborhood opinion.

The initial model was run using the measures of respondent's attitudes and attributes obtained in the before study CR1 (implicitly assuming these would be unvarying characteristics of the individual). Results from the initial model are shown in Table VI. Only two of the factors were significant in the model. Based on type III tests, the effect of survey round was highly significant $(p<0.001)$, as was household association with the trucking industry-respondents associated with trucking had lower annoyance scores than those who were not. Noise sensitivity and overall opinion of the neighborhood were not significant, nor were knowledge of the trial or of consultations with government, nor expectations the trial would result in improvement.

The potential influence of noise sensitivity (and overall opinion of neighborhood quality) can be examined further. Noise sensitivity is generally regarded as a characteristic of the individual (Benfield et al., 2012) and both noise sensitivity and opinion of neighborhood quality were entered in the initial model as a fixed value for each individual measured at the time of the first survey round CR1. However, re-measurements of both noise sensitivity and neighborhood opinion were also available at each of the subsequent surveys (CR2-CR5). Based on separate mixed model analyses using the repeated measures of individual noise sensitivity and opinion of neighborhood quality as dependent variables respectively, tests confirm that there was a marginally significant difference in the mean sensitivity score of the panel across the five survey rounds $\left(F_{4,171.8}=1.947, p=0.04\right)$ but no significant difference in the mean neighborhood quality score $\left(F_{4,197.4}=1.947\right.$, not significant). Despite this, when a new model was fitted to annoyance with late night and very early morning traffic noise, but this time using the repeated measures of sensitivity and neighborhood quality, both are significant in the model (Table VII). Annoyance scores increased as the individual noise sensitivity scores increased and as overall opinion of the neighborhood changed from excellent to very poor.

This finding does suggest, as discussed by Brown and van Kamp (2009b), that change in human response associated with changes in exposure may be related to concomitant change in the moderating variables. For the current study, the effect of a change in noise sensitivity was relatively small with a shift from low to high noise sensitivity moderating annoyance scores +0.6 points on the annoyance scale,

TABLE VI. Output from the initial model run with individual annoyance scores in the late night and very early morning as the dependent variable, with survey round and other fixed factors as listed. The fixed factors were measured at the time of the before study, CR1. (df, degrees of freedom; Num., numerator; Denom., denominator; Sig., significance.)

\begin{tabular}{lrrrrr}
\hline \hline & \multicolumn{5}{c}{ Type III tests of fixed effects } \\
\cline { 2 - 5 } & \multicolumn{2}{c}{ df } & & \\
\cline { 2 - 5 } Source & Num. & Denom. & F & Sig. \\
\hline Survey round & 4 & 188.402 & 9.221 & $<0.001$ \\
Noise sensitivity & 2 & 86.919 & 2.145 & 0.123 \\
Overall neighborhood opinion & 3 & 84.466 & 2.037 & 0.115 \\
Associated with trucking industry & 1 & 77.740 & 11.353 & $<0.001$ \\
Awareness of consultations & 1 & 71.813 & 2.993 & 0.088 \\
Knew of truck strategy trial & 1 & 78.664 & 1.822 & 0.181 \\
Expectation of improvement & 2 & 77.260 & 0.326 & 0.723 \\
Survey * noise sensitivity & 8 & 189.854 & 1.811 & 0.077 \\
Survey * neighborhood opinion & 12 & 188.472 & 1.542 & 0.112 \\
\hline \hline
\end{tabular}


TABLE VII. Model output with individual annoyance score in the late night and very early morning as the dependent variable, but with noise sensitivity and opinion of neighborhood quality re-measured at each survey round CR1 to CR5.

Type III tests of fixed effects

\begin{tabular}{|c|c|c|c|c|}
\hline \multirow[b]{3}{*}{ Source } & \\
\hline & \multicolumn{2}{|c|}{ df } & \multirow[b]{2}{*}{$F$} & \multirow[b]{2}{*}{ Sig. } \\
\hline & Num. & Denom. & & \\
\hline Survey round & 4 & 195.016 & 12.182 & $<0.000$ \\
\hline Noise sensitivity (at each survey round) & 2 & 287.410 & 3.953 & 0.02 \\
\hline Overall neighborhood quality (at each survey round) & 3 & 293.996 & 5.590 & $<0.001$ \\
\hline Associated with trucking industry & 1 & 97.790 & 12.815 & $<0.001$ \\
\hline
\end{tabular}

and a change in opinion of neighborhood quality somewhat larger; a shift from excellent to very poor is associated with a change in annoyance score of -2.8 , but nearly all of this change occurred with the last increment on the neighborhood quality scale from poor to very poor.

With the model fitted with four significant factors (as in Table VII) estimated marginal means (EMM) of annoyance in the late night and very early morning at each round of survey during the truck diversion trial are shown in Fig. 3. The EMM of annoyance dropped sharply after the beginning of the trial, staying low up to some 12 months after the trial began, then with some recovery in annoyance scores towards the end of the trial. Confidence limits for the EMM are shown in Fig. 3. These intervals widen with successive surveys, reflecting the reducing size of the panel over the study period. Using the Bonferroni adjustment for multiple comparisons, post hoc comparisons of the EMM shows a reduction from CRI to CR2 of 1.1 points on the 10-point annoyance scale. The reduction in annoyance from CR1 to CR2, CR3, and CR4 were all highly significant $(p<0.001)$ with the difference from CR1 being $1.1,2.2$, and 1.0 points (of the 10 point annoyance scale). By the final survey round (CR5) the EMM of night-time annoyance score was still 0.4

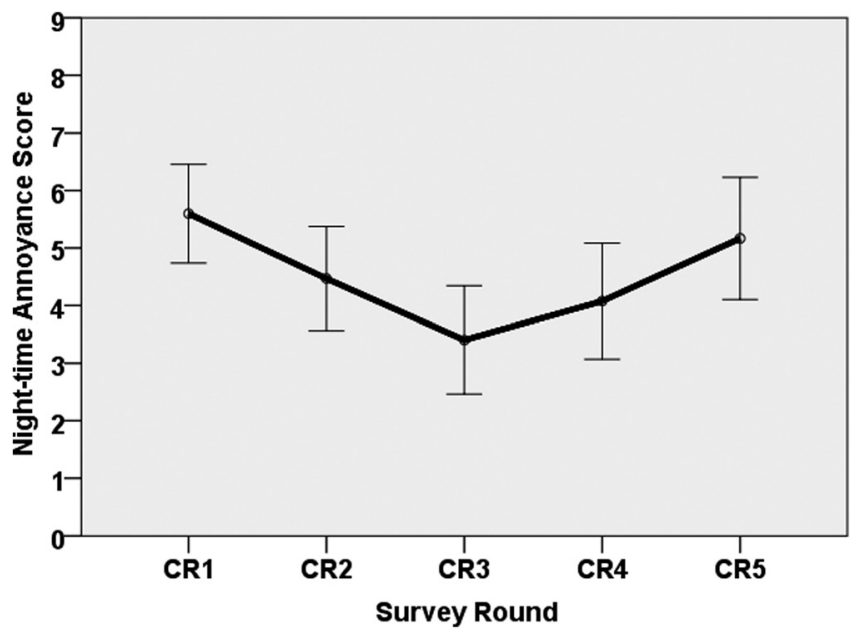

FIG. 3. Change in the estimated marginal means of the late night and very early morning annoyance scores of the panel across the five rounds of survey spanning the period of the truck diversion trial. The variables included in the model are those shown in Table VII. The bars are 95\% confidence intervals for the estimated marginal means. The confidence intervals lengthen in successive surveys because of the progressive reduction in panel size. points lower than at the before survey, though this difference was not significant.

In summary, it can be concluded that the annoyance of the panel in the late night and very early morning did change significantly during the truck diversion trial period $\left(F_{4,170.4}=12.18, p<0.001\right)$.

\section{Changes in the proportion of the panel highly annoyed and in activity interferences}

The changes in outcomes over time can also be examined in the percentage of the panel who were highly annoyed at each survey round. Figure 4 shows that, starting from a base of $58 \%$ of the panel highly annoyed with road traffic noise in the late night and very early morning in the before study, the percentage dropped to $18 \%$ at CR3 and CR4, then increased to $42 \%$ by the end of the trial period. This pattern of change in group annoyance in Fig. 4 follows that of the EMMs in Fig. 3.

Changes in the reporting of interference effects caused by road traffic noise over the different survey rounds is shown in Fig. 5. While the frequency of activity interference was nominally ordinal, EMMs of the frequency of interference can still be calculated by applying a series of linear mixed models, each with an activity interference as the dependent variable. The EMMs for shutting windows because of noise, communication interference, sleep disturbance, and being startled by noise, at each survey round, are shown in Fig. 5. The legend in Fig. 5 shows whether there was, overall, a significant difference in the incidence of activity

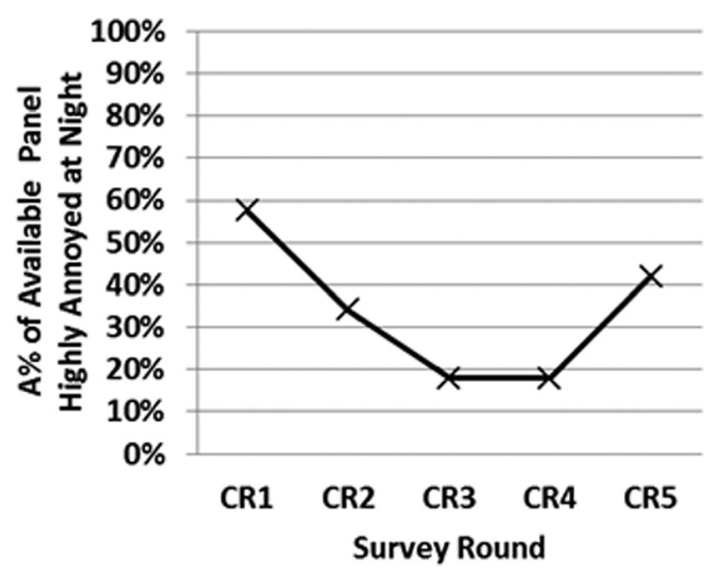

FIG. 4. Changes in the percentage of the panel (the panel size varies across survey rounds as per Table IV) who were highly annoyed at night. 


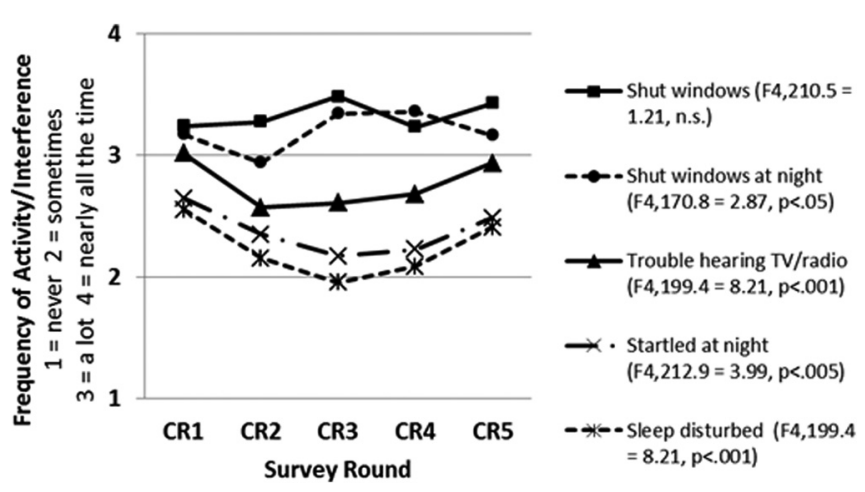

FIG. 5. Estimated marginal means of the frequency of different activity interferences reported by the panel at each survey round.

interferences across the rounds of the survey-based on linearly independent pairwise comparisons among the EMMs.

Figure 5 confirms that the incidence of shutting windows because of traffic noise was high at all surveys. However, for interference with hearing TV/radio/telephone, self-reports of sleep disturbance, and being startled at night, the EMMs broadly follow the pattern of changes in nighttime annoyance scores (Figs. 3 and 4) over the five successive surveys-initially dropping after the before study, remaining at lower levels for a year after the truck reduction trial commenced, then increasing, but still not returning to the frequency reported in the before study near two years after the trial began.

\section{Respondents' assessment of change in noise effects experienced since before the truck diversion strategy commenced}

Subsequent to reporting their annoyance scores and levels of activity interference with current conditions in the surveys, respondents were also asked to judge, at CR2-CR5, if they had noticed a difference in the noise in the late night and very early morning between current conditions and the conditions that existed before the truck diversion commenced. Table VIII shows that, over all repeated surveys, half or more of the panel noticed a difference, and between $21 \%$ and $37 \%$ of the panel reported they were less often sleep disturbed or less often startled at night than before the intervention. These reports confirm the positive response of the panel already seen in Figs. 3-5 regarding reduced effects of road traffic noise over the truck diversion strategy period.

Counter to this overall consistency in responses across CR2 to CR4, by survey round CR5 some of the panel began reporting closing of windows $(9 \%)$, having sleep disturbed $(30 \%)$ or being startled in the late night and very early mornings $(24 \%)$, more often than they did before the truck strategy began. The likely explanation is that CR5 was conducted 22 months (or nearly two years) after the implementation of the truck diversion, and some panel members may have been comparing their current conditions, not with before-change conditions two years ago, as intended, but with the improved situation they had experienced immediately after the trial began. This anomaly at CR5 was a direct consequence of the community survey being extended by authorities for a further interval beyond its planned termination at CR4.

In summary it can be concluded that, not only did the night-time annoyance of the panel change significantly during the truck diversion trial, but that their reported frequency of interferences with activities caused by traffic noise did too. These analyses of community responses over the five rounds of the survey provide convincing evidence that the community living adjacent to the study roadway responded positively to the truck diversion strategy. The reductions in

TABLE VIII. Respondents' assessments as to whether noise from the roadway and its effects had changed since before the truck diversion trial began. The percentages are of the respondents remaining in the panel at the time of the round (as per Table IV).

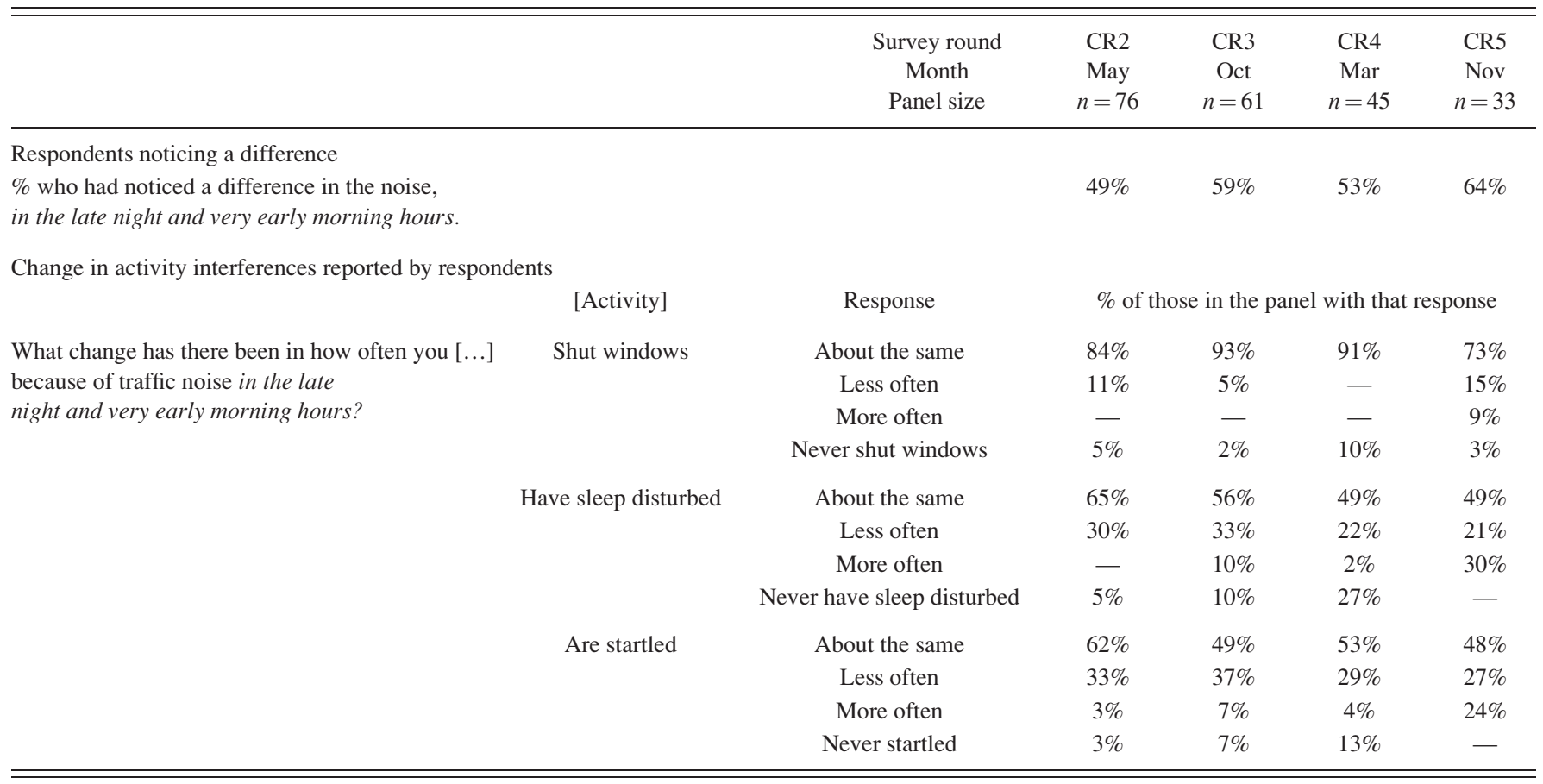


response were consistent up to 12 months after the truck diversion strategy commenced, but then trended upwards towards the end of the 22 months period of the trial.

\section{PLAUSIBLE EXPLANATIONS OF THE LONGITUDINAL CHANGE IN ANNOYANCE AND ACTIVITY INTERFERENCES}

There are several plausible explanations for the observed changes in community response to noise during the trial.

(1) The positive community response was due to a change (reduction) in levels of road traffic noise as a result of the truck diversion.

(2) The positive response was an artifact of the repeated surveying of respondents.

(3) The outcome may have been influenced by non-random drop out of panel members.

(4) The positive response was a change effect, possibly due to changes in attitudinal factors which are moderators of annoyance, over the duration of the trial.

(5) The positive response was due to a change in the number of articulated heavy vehicles (hence in the number of noise events) in the night-time road traffic stream.

Each of these is examined below.

\section{A. Change in the levels of traffic noise exposure}

The noise exposures at four different dwellings representing the exposure of members of the panel were measured (Brown et al., 2009) on six occasions, NL1-NL6. Measurements were conducted for either two days or four days at each of NL1-NL6, with values shown in Table IX being the mean across these measurement days. Table IX shows the $L_{A 10(18 \mathrm{~h})}$ indicator and, because the toll-free trial operated from 22:00 $\mathrm{h}$ to $05: 00 \mathrm{~h}$, a 7-h equivalent noise level indicator, $L_{\text {Aeq(7h). }}$ The latter approximates the $L_{\text {night }}$ indicator adopted by the European Union, though for a period one hour shorter, and commencing one hour later, than the $8 \mathrm{~h}$ utilized there.

Table IX shows that, while there were differences in levels between the dwellings because they were different

TABLE IX. $L_{A 10(18 \mathrm{~h})}$ and $L_{A \text { eq(7h) }}$ free field noise levels at the location of the facade of four dwellings of the panel. Each level is the mean of measurements over several days. Six repeated measurements, NL1-NL6, were conducted at each of the four dwellings over the period of the truck diversion trial.

\begin{tabular}{lcccccc}
\hline \hline & NL1 & NL2 & NL3 & NL4 & NL5 & NL6 \\
\hline Dwelling & & \multicolumn{5}{c}{$L_{A 10(18 \mathrm{~h})} \mathrm{dB}$} \\
1 & 73 & 73 & 73 & 73 & 73 & 73 \\
2 & 69 & 69 & 68 & 68 & 68 & 69 \\
3 & 77 & 78 & 78 & 77 & 77 & 77 \\
4 & 74 & 75 & 75 & 74 & 76 & 74 \\
Dwelling & & & & & & \\
1 & 63 & 63 & 63 & 63 & 63 & 63 \\
2 & 60 & 60 & 60 & 60 & 58 & 60 \\
3 & 68 & 68 & 67 & 67 & 67 & 68 \\
4 & 66 & 66 & 66 & 67 & 67 & 66 \\
\hline \hline
\end{tabular}

distances from the study roadway, there was minimal difference in levels between successive monitoring rounds at all sites. Within usual measurement limits, there is effectively no change in noise exposure across all of the monitoring rounds which span the same period as do the community response measurements (CR1-5).

The conclusion is that the changes in community responses to road traffic noise over the period of the truck diversion trial was not caused by change in the exposure of the community to road traffic noise, even when traffic noise levels were measured as $L_{A \text { eq(7h) }}$ over the 22:00 h to 05:00 h period of the truck diversion.

\section{B. Repeated surveying of the same respondents}

It is possible use of a panel design, with repeated interviews of the same respondents, could have led to demandresponse bias or response set that resulted in the observed changes in community response. Job (1988) had suggested demand-response bias could be a problem where a panel is interviewed before and after a change, with respondents likely to perceive that the interviewer is expecting (demanding) a changed reaction. There is no recent work that deals with this issue, but Brown and van Kamp (2009b) concluded, from a review of past noise survey evidence, that demandresponse bias generated by repeated questioning in noise annoyance surveys is unlikely. The limited evidence included work by Fields et al. (2000) who analyzed a range of panel studies, concluding they do not appear to introduce survey-resurvey bias in noise response, particularly if repeated surveys are at least one month apart; Jonsson and Sörensen (1973); and Fidell et al. (1985), who reported that after-change annoyance responses (for short-term annoyance) were similar over three repeated rounds of interviews (in what they regarded as being tantamount to a panel study) conducted over three months. Fidell and Jones (1975) also found no difference in annoyance responses between a panel (interviewed three times by telephone before and after a change in flight paths at Los Angeles airport) and independent control samples at the first and third interviews. Demand-response effects are thus unlikely to have generated the changes in noise effect response observed in this study.

\section{The outcome may have been influenced by non-random drop out of panel members}

Could non-random drop out from the panel have contributed to the observed longitudinal change in responses? For example, could it be that those who were more highly annoyed chose not to continue in the study after the first round, thus leading to lower mean scores of the panel in successive rounds? This has been tested, in part, by comparing annoyance reported at the initial survey CR1 of those who chose to then continue in the panel with those who did not. The distribution of responses categorized as highly annoyed, annoyed, and a little annoyed for those who dropped out after the initial survey was found not to differ systematically from those who continued in the panel to CR2 (chi-square test of independence $=0.93,3 \mathrm{df}, p=0.18$ ). This suggests 
that panel drop out is unlikely to have played a major role in the observed longitudinal change in responses.

\section{Change in attitudinal factors which are moderators of annoyance}

One potential explanation for the phenomenon of a change-effect in intervention studies is that attitudinal variables, which are known to moderate annoyance, may themselves change over time (Job, 1988; Brown and van Kamp, $2009 a, b)$. In the current study, the finding of a reduction in annoyance in the panel despite there being no observed change in noise exposure over the trial, initially suggests that this was a change-effect. However, change in two moderator variables, sensitivity and neighborhood opinion, can be discounted as the driver for the panel's change in response across the trial because, as reported in Sec. IV C 1 above, there was only a marginally significant difference in the mean sensitivity score of the panel across the five survey rounds and no significant difference in the mean neighborhood quality score. The possibility remains, however, that attitudes to authorities and expectations changed over time, with subjects first being optimistic about the truck management strategy followed by disappointment. There was no tracking of attitudes to authorities or respondents' expectations throughout this study.

\section{E. Change in the number of articulated heavy vehicles using the corridor at night}

Measurement were also conducted longitudinally on the traffic volume and composition on the corridor over the period of the truck diversion (TF1-6 in Table II). Traffic could enter or leave the corridor in various places, and traffic flows were not identical on every section of its length. The mean total two-way weekday traffic flow on sections ranged from 41000 to 51000 vehicles per day, with trucks constituting some $12 \%$ to $15 \%$ of the total traffic, and articulated trucks [Austroads (undated), classes 6 to 12] some 5\% of total traffic.

As the truck diversion strategy was directed at articulated vehicles, examination of the traffic counts was directed largely towards whether there were changes in the numbers of articulated vehicles on the corridor at night throughout the period of the trial. Three things should be noted regarding the truck counts. First, the truck diversion strategy applied to the $11.5 \mathrm{~km}$ corridor as a whole, meaning successful diversion of any vehicle from the corridor resulted in its removal from all roadway sections. Second, there is high day to day variability in heavy vehicle flows on this corridor depending on factors related to seasonal flow of commodities, shipping deliveries, restocking schedules, etc. Third, over the near two years that the diversion strategy was directed at reducing truck flows on the corridor, traffic flows in the area as a whole were continuing to grow as a result of both population and economic growth, at an annual rate of some $3.5 \%$.

Figure 6 shows the available manual two-way counts of articulated vehicles at two sites on the corridor, over TF1-TF6, throughout the truck diversion trial. The large inherent variability from day to day is evidenced by the error

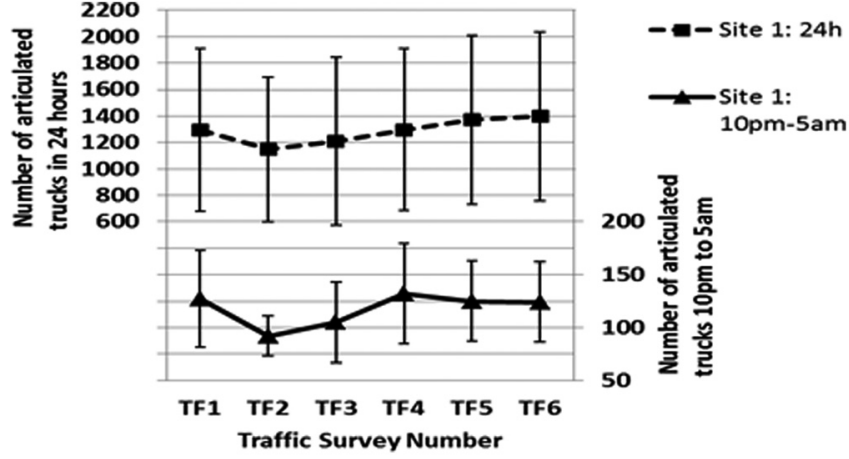

(a)

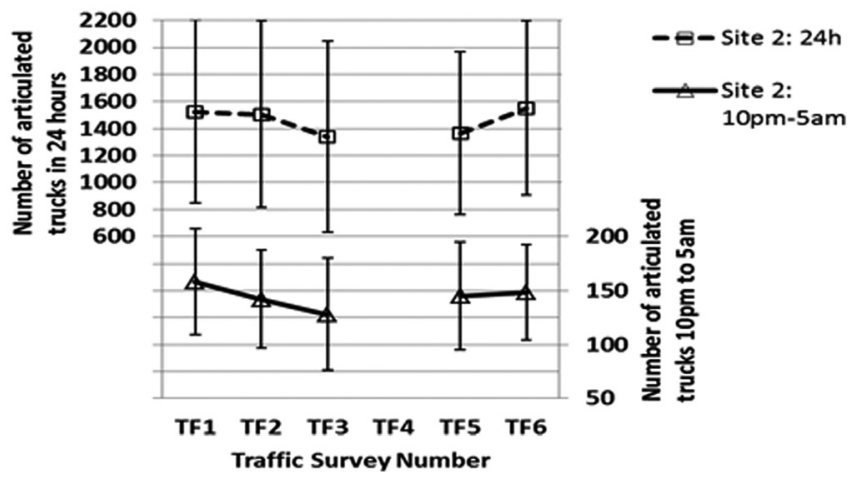

(b)

FIG. 6. Number of articulated trucks (over $24 \mathrm{~h}$, and between 22:00 h and 05:00 h) in the traffic stream at traffic surveys TF1 to TF6 over the 22 months of the truck diversion study. The plotted values are the mean of repeated counts over several days at each traffic survey, and show $+/-1$ standard deviation bars. The results are from two traffic counting sites on the study corridor. Traffic counts were not available for site 2 at TF4.

bars $(+/-1$ standard deviation are shown in the figure) about the plotted mean number of articulated vehicles. At each of the two sites, the numbers of articulated vehicles on the roadway in $24 \mathrm{~h}$, and between 22:00 $\mathrm{h}$ and 05:00 h, are shown separately. While the variability of the number of truck passages is high, at both sites there is a discernible drop in the number of articulated vehicles on the roadway, during the late night and early morning and over $24 \mathrm{~h}$, when the truck diversion began after TF1. However, Fig. 6 also shows that, after the initial reduction in articulated trucks in the first year or so of the truck diversion, this becomes increasingly buried in the overall annual growth in traffic. By the end of the trial, the numbers of articulated trucks on the study roadway have increased to the extent they approach the numbers present before the truck diversion trial began.

The trends in the number of articulated vehicles using the study roadway from 22:00 $\mathrm{h}$ to $05: 00 \mathrm{~h}$ over the period of the truck diversion is remarkably similar to the trends in annoyance with traffic noise in the late night and very early morning reported by the panel (Figs. 3 and 4) and their reports of traffic noise interferences (Fig. 5). This is strongly suggestive of a causal link between the number of articulated vehicles on the study roadway in the late night and very early morning, and community response to noise in this same period. 


\section{DISCUSSION}

In summary, the analyses above have demonstrated that community response to road traffic noise, in both annoyance and noise interference effects, changed over the duration of the truck diversion strategy. It also demonstrated that, while there were no changes in the conventional noise exposure measures over this period, the number of articulated vehicles using the corridor in the late night and very early morning also changed with a pattern, over the duration of the truck diversion, similar to that of the noise responses.

The causal link between the number of articulated vehicles at night on the study corridor and the panel's noise responses is likely to be through the panel's awareness of the trucks as noise events detected within the traffic noise stream, particularly at night when background levels are low. Articulated vehicles on the study corridor are a major, though not the only, source of high-level traffic noise events in the traffic stream (Brown and Tomerini, 2011).

The notion that the number and level of noise events in a road traffic noise stream may drive human responses to traffic noise is not new. There have been persistent assertions that the presence of heavy vehicles may separately contribute to annoyance (Langdon, 1976a,b; Björkman, 1991), and either the number, or proportion, of heavy vehicles in the road traffic stream has been identified as determinants of annoyance responses over and above their contribution to equivalent sound levels (Lercher and Kofler, 1996; Öhrström, 2004; Bannerjee et al., 2009; Dratva et al., 2010) - though Versfeld and Vos (2002) suggest otherwise. Noise events also figure in the Environmental Noise Directive (European Commission, 2002) which requires assessment of $L_{\mathrm{den}}$ and $L_{\text {night }}$, but additionally allows the use of noise events as supplementary noise indicators-presumably to limit sleep disturbance. The Night Noise Guidelines for Europe (WHO, 2009) also note the potential health relevance of the instantaneous effects caused by noise events. The European Commission (2004) notes that noise scenarios which differ in number, acoustical properties, and placement of noise events, may calculate to the same $L_{\text {night }}$, but then differ substantially in their effects on people.

The current study provides evidence that, while reduction of the number of heavy vehicles in the traffic stream did not result in change in the noise exposure of the study panel $\left(L_{\text {night }}\right)$, the panel did respond to a decrease in the number of noise events in the night-time traffic stream by persistent and significant reductions in both their annoyance scores and their reports of noise interference effects.

The consequence is that the number and level of noise events needs to be considered as a noise indicator in the face of non-responsiveness of conventional measures of road traffic noise to interventions such as truck restriction strategies.

\section{CONCLUSIONS}

The specifics of this noise management intervention were unusual. The whole of the study population was exposed to high levels of road traffic noise, but the noise management strategy could be directed only at reducing truck noise during the late night and very early morning, with no changes at other times of the day. The truck diversion strategy for the study roadway comprised the removal of the toll for trucks on a parallel toll road, and this produced changes in noise effects reported by the community living adjacent to the study roadway. This occurred even though the diversion strategy did not change the noise exposures along the study roadway —at least as measured using conventional road traffic noise indicators of $L_{A 10}$, and $L_{\text {night. }}$ The positive response in the panel can be attributed to the reduction in the number of heavy vehicle noise events in the late night and very early morning period, with events associated with the articulated trucks likely to represent a considerable proportion of the traffic noise events from the roadway at night. The conclusion is that measures of the number and level of noise events in road traffic streams warrants attention as an acoustical indicator related to human response to road traffic noise, at least in the night-time hours.

The effect of the truck diversion strategy of reducing the affected community's high adverse response to noise was persistent after the original reduction in night-time articulated vehicles. However, the annual growth rate of traffic on the study roadway was also persistent. Over the next two years of the study, the number of articulated trucks at night climbed back near to the numbers before the intervention, with the truck reduction achieved by the diversion subsumed in the annual traffic flow increases.

The close tracking of annoyance and noise interference responses in the community with these traffic changes was remarkable, providing confidence both in the community's ability to detect and respond to relatively small changes in numbers of noise events at night, and in the ability of noise annoyance scales and noise interference scales to measure the effects of such changes.

The importance of longitudinal studies of outcomes to assess the effect of noise management interventions has been demonstrated. Measures of outcomes are required, not just before and after the intervention, but as a time series of repeated measures extending for considerable periods after any intervention. The model proposed by Brown and van Kamp (2005) is an appropriate starting point for the design of such studies.

\section{ACKNOWLEDGMENTS}

The work of D. Pitts in the overall study and in the analysis of traffic data reported here is acknowledged, as is that of R. Troutbeck. The noise level measurements were conducted by Heggies Pty Ltd. Department of Transport and Main Roads, Queensland, initiated and funded the studies on which this paper is based.

\footnotetext{
${ }^{1}$ After two years of trial of the diversion strategy, traffic management changed to one of restricting through-movements of heavy vehicles on the corridor with $24 \mathrm{~h}$ enforcement by automatic number plate recording at both ends of the corridor. This truck restriction system detects heavy vehicles that travel the length of the corridor in less than a specified time interval, targeting truck through-movements on the corridor, but allowing trucks that have local business to continue to utilize it without sanction. This truck restriction strategy affected only certain classes of heavy vehicles using the route, with no effect on non-truck traffic flows. The adoption of the truck restriction strategy was influenced by the results reported here concerning the reduced noise effects resulting from the truck diversion trial.
} 
Austroads, Austroads Vehicle Classification System, http://www.whyalla.sa. gov.au/webdata/resources/files/austroads_classes.pdf (Last viewed December $16,2014)$.

Bannerjee, D., Chakraborty, S. K., Bhattacharyya, S., and Gangopadhyay, A. (2009). "Attitudinal response towards road traffic noise in the industrial town of Asansol, India," Environ. Monit. Assess. 151, 37-44.

Belojević, G., Jakovljević, B., and Aleksić, O. (1997). "Subjective reactions to traffic noise with regard to some personality traits," Environ. Int. 23, 221-226.

Benfield, J. A., Nurse, G. A., Jakubowski, R., Gibson, A. W., Taff, B. D., Newman, P., and Bell, P. A. (2012). "Testing noise in the field: A brief measure of individual noise sensitivity," Environmental Behavior Report No. 0013916512454430, 1 August.

Björkman, M. (1991). "Community noise annoyance: Importance of noise levels and the number of noise events," J. Sound Vib. 151, 497-503.

Brown, A. L., and Tomerini, D. (2011). "Distribution of the noise level maxima from the pass-by of vehicles in urban road traffic streams," Road Transp. Res. 20(3), 41-54.

Brown, A. L., Tomerini, D., Carroll, J., and Scott, N. D. (2009). "Nonresponsiveness of conventional measures of road traffic noise to an urban truck restriction strategy," Proceedings of InterNoise 09, Institute of Noise Control Engineering, Ottawa, Canada, pp. 565-574.

Brown, A. L., and van Kamp, I. (2005). "Towards a design for studies of response to a change in noise," Proceedings of InterNoise 05, Institute of Noise Control Engineering, Rio de Janeiro, Brazil, pp. 2958-2967.

Brown, A. L., and van Kamp, I. (2009a). "Response to a change in transport noise exposure: A review of evidence of a change effect," J. Acoust. Soc. Am. 125(5), 3018-3029.

Brown, A. L., and van Kamp, I. (2009b). "Response to a change in transport noise exposure: Competing explanations of change effects," J. Acoust. Soc. Am. 125, 905-914.

Dratva, J., Zemp, E., Dietrich, D. F., Bridevaux, P.-O., Rochat, T., Schindler, C., and Gerbase, M. W. (2010). "Impact of road traffic noise annoyance on health-related quality of life: Results from a populationbased study," Qual. Life Res. 19, 37-46.

European Commission (2002). Relating to the Assessment and Management of Environmental Noise, Council Directive (EC) 2002/49/EC of 25 June 2002.

European Commission (2004). Position Paper on Dose-effect Relationships for Night Time Noise, Working Group on Health and Socio-Economic Aspects, http://ec.europa.eu/environment/noise/pdf/positionpaper.pdf (Last viewed December 16, 2014)

FHWA (2008). Traffic Noise Model Version 2.5, http://www.fhwa.dot.gov/ environment/noise/traffic_noise_model/tnm_v25/ (Last viewed October 17, 2013).

Fidell, S., Horonjeff, R., Mills, J., Baldwin, E., Teffeteller, S., and Pearsons, K. (1985). "Aircraft annoyance at three joint air carrier and general aviation airports," J. Acoust. Soc. Am. 77(3), 1054-1068.

Fidell, S., and Jones, G. (1975). "Effects of cessation of late-night flights on an airport community," J. Sound Vib. 42(4), 411-427.

Fields, J. (1993). "Effect of personal and situational variables on noise annoyance in residential areas," J. Acoust. Soc. Am. 93, 2753-2763.

Fields, J. M., Ehrlich, G. E., and Zador, P. (2000). "Theory and design tools for studies of reactions to abrupt changes in noise exposure," Report No. NASA-CR-2000-210280, NASA Langley Research Center, Hampton, VA.
Griefahn, B., and Spreng, M. (2004). "Disturbed sleep patterns and limitation of noise," Noise Health 6(22), 27-33.

Guski, R. (1999). "Personal and social variables as co-determinants of noise annoyance," Noise Health 3, 45-56.

Hill, E. M. (2012). "Noise sensitivity and diminished health: The role of stress-related factors," Doctoral dissertation, AUT University, http://aut. researchgateway.ac.nz/bitstream/handle/10292/4755/HillEM2.pdf?sequence $=4 \&$ isAllowed $=\mathrm{y}$ (Last viewed May 21, 2014).

Hoeger, R., Schreckenberg, D., Felscher-Suhr, U., and Griefahn, B. (2002). "Night-time noise annoyance: State of the art," Noise Health 4(15), $19-25$.

IMAGINE (2007). "The noise emission model for European road traffic," deliverable 11, http://www.imagine-project.org/bestanden/IMA55TR060821-MP10\%20-\%20IMAGINE\%20Deliverable\%20D11.pdf (Last viewed October 17, 2013).

ISO (2003). ISO/TS 15666:2003, Acoustics-Assessment of Noise Annoyance by Means of Social and Socio-acoustic Surveys (International Organization for Standardization, Geneva).

Job, R. F. S. (1988). "Over-reaction to changes in noise exposure: The possible effect of attitude," J. Sound Vib. 126(3), 550-552.

Job, R. F. S. (1999). "Community response to noise: A review of factors influencing the relationship between noise exposure and reaction," J. Acoust. Soc. Am. 83, 991-1001.

Jonsson, E., and Sörensen, S. (1973). "Adaptation to community noise-a case study," J. Sound Vib. 26(4), 571-575.

Langdon, J. (1976a). "Noise nuisance caused by road traffic in residential areas: Part I," J. Sound Vib. 47, 243-263.

Langdon, J. (1976b). "Noise nuisance caused by road traffic in residential areas: Part II," J. Sound Vib. 47, 265-282.

Lercher, P., and Kofler, W. W. (1996). "Behavioral and health responses associated with road traffic noise exposure along alpine through-traffic routes," Sci. Total Environ. 189/190, 85-89.

Miedema, H. M. E., and Oudshoorn, C. G. (2001). "Annoyance from transportation noise: Relationships with exposure metrics DNL and DENL and their confidence intervals," Environ Health Persp. 109, 409-416.

Miedema, H. M. E., and Vos, H. (1999). "Demographic and attitudinal factors that modify annoyance from transportation noise," J. Acoust. Soc. Am. 105, 3336-3344.

Miedema, H. M. E., and Vos, H. (2003). "Exposure-response relationships for transportation noise," J. Acoust. Soc. Am. 113, 1492-1504.

Öhrström, E. (2004). "Longitudinal surveys on effects of changes in road traffic noise-Annoyance, activity disturbances, and psycho-social wellbeing," J. Acoust. Soc. Am. 115(2), 719-729.

Transportation Research Board (2003). "Strategies for managing increasing truck traffic," National Cooperative Highway Research Program, Synthesis 314 .

van Kamp, I., and Brown, A. L. (2013). "Response to change in noise exposure: An update," Proceedings of Acoustics 2013, the Annual Conference of the Australian Acoustical Society, CD-ROM, November 2013.

Versfeld, N. J., and Vos, J. (2002). " $A$-weighted equivalent sound level as a predictor of the annoyance caused by road traffic consisting of various proportions of light and heavy vehicles," J. Sound Vib. 253, 389-399.

WHO (2009). Night Noise Guidelines for Europe, WHO Regional Office for Europe, Copenhagen, http://www.euro.who.int/_data/assets/pdf_file/ 0017/43316/E92845.pdf (Last viewed May 21, 2013). 